\title{
"Create fast, sell fast": retailers find speed to market and savings with DAM
}

\section{Danielle Cass}

is Director of Public Relations at Xinet Inc. Formerly a newspaper reporter at The Oakland Tribune, Cass has interviewed over 100 Xinet customers in North America and Europe, including those at Macy's, Ogilvy \& Mather, McCann Erickson, Time, Sports Illustrated and BBDO. Cass serves on the Editorial Board of the Journal of Digital Asset Management. She is a graduate of the Northwestern University Medill School of Journalism.

Keywords: enterprise digital asset management, retailers, consumer product manufacturers, marcom, speed to market, brand control, return on investment, Macy's, CompUSA, Jarden, Bloomingdale's, metadata

Abstract Digital Asset Management (DAM) enables retailers to get products on the shelf faster by shortening the cycle time between shooting the initial photograph of a product and getting that image into a direct mail piece, an in-store point of purchase display (POP), a print advertisement, a retail Web site, or on the side of a merchandise package and onto store shelves.

Journal of Digital Asset Management (2006) 2, 249-253. doi:10.1057/palgrave.dam.3650040

\section{INTRODUCTION}

As the retail industry marches into the digital age, more retailers and consumer product manufacturers have seized control of their imagery and branding with Digital Asset Management (DAM), increasing their speed to market and savings as a result.

Retailing and consumer giants who have gained an immediate return on investment by bringing DAM in-house include Macy's, Bloomingdale's, CompUSA, Jarden (whose brands include Sunbeam, Mr. Coffee and Oster) and The Topps Company, the world's largest candy and collectible sports trading card manufacturer.

"If you can create fast, you can sell fast," said Shani Schechter, End User Support Manager at Macy's East.

Digital asset management enables retailers to get products on the shelf faster by shortening the cycle time between shooting the initial photograph of a product and getting that image into a direct mail piece, an in-store point of purchase display (POP), a print advertisement, a retail website, or on the side of a merchandise package and onto store shelves.

"It's important for us to get our products out on the shelf fast, and there is no way we could do that quickly without Xinet WebNative," said Greg A. Pedersen, Graphic Services LAN Administrator at Topps, a $\$ 300 \mathrm{~m}$ company that makes Bazooka Bubble Gum, Garbage Pail Kids and collectible baseball, football and basketball trading cards.

"Xinet WebNative Venture gives us an advantage because it helps us keep track of all our brands and products, and streamlines production so that our film dates have closed a lot faster," Pedersen said.

Like Macy's and all the companies mentioned in this article, Topps uses Xinet WebNative for DAM. Xinet WebNative dramatically streamlines the collection, access, production, distribution and archiving of graphic media for advertising, publishing and corporate communications. This server-neutral, client-neutral system accelerates the creative and production workflow by breaking down barriers between staff, vendors and clients - providing powerful tools that can be used to automate notification, distribution and production.

Xinet WebNative Venture marries dynamic content distribution and manufacturing systems into one powerful asset management tool. Xinet WebNative Portal is a display layer for the total 
Xinet solution. With WebNative Portal, companies produce secure, branded Web dashboards that can search and access assets in multiple-server WebNative Venture asset banks.

By using a common DAM work environment, people can contribute to the system, uploading images, documents and layouts, while simultaneously using elements cataloged in the system, as designers do by dragging-and-dropping low-resolution images through a Web interface directly into layouts on their desktops. The Xinet solution enhances existing creative and production workflows by making image files available globally and by automating steps in the creative and production process.

By creating a singular access point for all images, brands and logos, WebNative DAM delivers many benefits for retailers and consumer manufacturers: Worldwide distributors access the same sales materials from any location; rights management is controlled; brand identities are enforced; and targeted variable data campaigns are closely tied to buying trends.

For example, Macy's East uses Xinet WebNative to organize and navigate its digital supply chain with an image library of 100,000 images that photographers, art directors, copywriters, image librarians and buyers access via the Web from different locations.

"We're saving tons of man hours. In one department alone, where we just catalogue images, we've saved 4,000 man hours. And that's just one of the many departments that use the system," Schechter said. "Bringing WebNative inhouse transformed how our advertising department operates and how the fashion department builds ads."

\section{SHORTENED DIGITAL SUPPLY CHAIN}

Bloomingdale's is another retailer that gained a return on its investment in the first year after installing its DAM system.

"Digital asset management drastically reduces the cycle time for retailers because the latest version of everything is instantly available to everyone in the supply chain," said Don Hunnewell, of Hunnewell Consulting in New York, formerly the Director of Technology and Prepress at Bloomingdale's, where he brought pre-press and digital asset management in-house for the department store chain.

"Everyone in the retail environment who touches the DAM system saves time with it: art directors, copy writers, the internet design team, the production department, the retouchers, the stylists, the merchants and buyers," said Hunnewell, who is now working with one of the world's biggest fashion and furniture retailers and catalogers to implement a DAM system there. "A retoucher is working on something while an art director is placing the image. When the retoucher is done, the art director's data is updated immediately, so everyone gets the latest, most accurate and up-to-date version immediately."

Using DAM, retailers can easily search and re-purpose images to create multi-format collateral and POP production workflows from a single image, or the original version of the "brand truth."

For example, a specific product shot of an applicance or a fashion model can be repurposed to appear in direct mail pieces, instore POP displays, print ads, Web content and packaging, while any changes made to that image are automatically updated to every version of the same original image.

"We're saving hundreds of hours a year," said CompUSA's advertising systems administrator Greg Weaver. "The dollar savings are significant. Selecting the right image for an advertisement used to involve someone finding literally all the available images of a product, and then emailing JPEGs to the appropriate parties until the correct image was approved. We were getting overwhelmed by the amount of work and sheer manpower it required."

CompUSA, a leading North American computer electronics retailer with $\$ 4.7 \mathrm{~b}$ in revenue, produces most of the company's newspaper ads, inserts, in-store POP displays, and online store imagery with Xinet WebNative at the Dallas headquarters. The advertising and marketing departments there must maintain branding requirements for CompUSA's brands and 200,000 products from hundreds of vendors, across 240 stores in 90 major metropolitan markets.

Xinet WebNative DAM provides an additional layer of functionality to brand management with custom image order and version control. 
Companies can maintain branding and imagery consistency through image file views linked to layout documents and relinking features that instantly update files with current images. A custom image order feature allows users to order, reformat and download art to fit the specs of any job, easily changing the file formats, DPI, color space and size.

Version control allows remote viewers to see the various versions of files in a Web browser, select from among those versions an approved or "current" version for production use, delete versions and download versions.

"A lot of branding control is based on workflow," said Weaver. "Having a DAM system like Xinet, where your workflow is more efficient and everyone has more time, helps bring control of branding back into the department."

With WebNative, the company's images are automatically repurposed. Designers can do in seconds what used to take minutes or even hours, said Weaver. When the merchandising department needs an image, they log in to the DAM system, look it up and retrieve it using WebNative.

"Now designers can focus on their work, and prepress can concentrate on production, instead of spending time duplicating images in different file formats," Weaver said.

\section{SEIZING CONTROL OF ASSETS}

Jarden Corporation, one of the world's largest manufacturers of toasters, electric kettles, coffee makers, fans, and blenders, saved thousands of dollars by bringing asset management in-house.

Jarden Consumer Solutions, part of $\$ 3.5 \mathrm{~b}$ Jarden Corporation, uses Xinet WebNative to organize and control its stable of brands: Sunbeam, Mr. Coffee, Oster, Rival, Holmes, Crock-Pot, Bionaire, FoodSaver, Health o meter, Patton, Seal-a-Meal, VillaWare and White Mountain.

"We have thousands of assets for 16 different brands that need to be accessed by remote Jarden offices all over the world, and by brand managers, suppliers, product managers, sales people in the field, and 26 advertising agencies," said Brad Straka, Director of Creative Services at Jarden Consumer Solutions.

"Our WebNative folder structure allows us to control which group of users has access to what area. With Creative Services departments in Boca Raton, Boston, Miami, Asia and Canada, we restrict the ability to download highresolution files from our working server until the files are final," Straka said. "For example, restricting high-resolution access by user name and password means that brand-approved images for the Sunbeam brand won't be used incorrectly by a manager of the Oster brand without permission."

The company had estimated that it would save $\$ 150,000$ in labor with its asset management system in the first year but actually hit that mark within three months.

"We're not only saving the time it took to upload everything but also the amount of people that are able to retrieve these assets so quickly and the amount of placements we are starting to see, so it was a huge pickup quick," Straka said.

Jarden first heard of Xinet WebNative through one of its advertising agencies, which was managing Jarden's assets with that DAM solution. Jarden executives soon realized that they wanted to control their own assets, so they brought WebNative in-house.

Jarden still works with its 26 ad agencies, but now Jarden uses the DAM solution to manage its branding and imagery, and to accelerate the sales process and increase sales.

"Speed to market was a huge issue in putting in the Xinet solution. Speed to market makes us competitive in the marketplace. If we can have any edge over our competition, we're going to take it, and Xinet really allowed us to have that edge," Straka said.

"Xinet has really helped with how we deploy our assets to our sales force. We used to burn CDs constantly because that's what they wanted: JPEG images of everything. Now we give them a password so they can login from any Web browser and access a little custom website we've made them."

Jarden takes its branding one step further by customizing the websites for each of its brands with WebNative Portal, a proxyserver-based front end for Web-accessed networks.

"We chose Portal because we wanted to customize the look and feel of each site, and because of the amount of people accessing the sites," said Straka. "When users go to each 
website, we want each page to be unique to that brand. Sunbeam should have a different look and feel than Mr. Coffee. The best way to customize it was with WebNative Portal."

\section{MACY'S ACCELERATES AD PRODUCTION}

When Macy's East went shopping for an enterprise digital asset management solution to bring in-house, they knew they had to have a system with an integrated database.

"When I came to Macy's two years ago, the workflow was struggling because we had a tremendous amount of images," said Macy's Shani Schechter. "We were looking for an enterprise asset management system that had a database like WebNative Venture, and we didn't find it anywhere else."

"My department is known for making instantaneous advertising, marketing and direct mail decisions. We've embraced technology that enables us monitor sales and put out new digital marketing campaigns on a daily or weekly basis," Schechter said. "With WebNative we can put together new, responsive advertising pieces very fast."

More responsive direct mail is possible because DAM alters the time frame of the retail production workflow.

"DAM changes the outcome of the constantly changing environment that a marketing plan can now live in. In the past, we faced time and press constraints. DAM gives you more flexibility when dealing with tight production and printing schedules," Schechter said. "With Xinet WebNative, you can make lastminute changes to advertising materials."

"Xinet is at the heart of our workflow," said Roman Master, IT Director for Macy's East and Advertex Communications.

Previously, the Home Store buyers had to go through a time-consuming process when choosing what to advertise. Now they just touch a thumbnail preview of the actual image they want to advertise from within WebNative Venture image repository.

"This saves an enormous amount of time and cuts down on mistakes," Master said.

Now fashion and product photographers shoot their photographs in one location, and then put the images on the WebNative server.
Within minutes, the art directors review the images via WebNative and choose the images they want.

"When we rolled this system out to the fashion department, I literally trained everyone in that department in a 15-minute class," Schechter said. "They went back to work and they were excited about the new system, which I was surprised about because to get an art director excited about something new in their workflow is rare. Art directors are on deadlines and they need to be available to deliver. They don't want to put anything new in their workflow that's not going to increase the speed of their ad production."

The art directors at Macy's East especially appreciate the ability to see large preview images that they can drag and drop into Adobe InDesign documents.

"Once they realized they could simply look through the pictures they want and drag them immediately into their ads to build them on the fly while photographers are still shooting pictures, they said 'This is incredible,"' Schechter said.

"Xinet was the only digital asset management database that we could pass information to and get information out of. Xinet's feature of allowing people to communicate with their database openly without administration is really important. It's the only system that I've seen with that feature," Macy's Workflow and Development Manager Christophe Dossat said.

"When figuring out how much time we have saved with WebNative, I wouldn't attach hours, I will attach days. It's about days. There used to be a three-day turnaround time in our image library department when they were cataloging images. Now there is no delay," he said.

"WebNative has really boosted our in-house fashion production," said Dossat. "Before WebNative, our fashion and product photographers were limited in how many photographs they could shoot per product because of the delay involved with cataloguing the photographs. Now the photographers are going crazy, shooting hundreds of pictures of each product because they know there is no more cataloguing delay. As soon as they leave the photo set and come into the cubicle, they $\log$ in to WebNative, see the thumbnail images 
of their pictures and call their managers to say: 'It's available."'

\section{DAM ERASES BOUNDARIES}

"Because of Xinet, it's like there are no boundaries between us and our remote locations and offsite partners," said Macy's Dossat. "The pictures are all there online. There is no more software that needs to be installed on somebody's desktop, no more connectivity issues or software configuration issues. All they need is an instant browser and they can see the thumbnail images right out of Xinet WebNative."

Before Macy's replaced its previous DAM system with the current solution, it was difficult to share images remotely.

"Now we have photographers who shoot the photographs in one location, art directors who pick up the photographs in another, an image librarian who is cataloging them, copy writers who are looking at those pictures, and buyers who are proofing those same ads. And they are all in different locations," Schechter said. "In the past, before WebNative, it was very difficult to get everybody on the same page at the same time. Now with WebNative, we are able to get everybody to look at the same product at the same time in 20 different locations if we need it to be."

Topps the global candy and sports trading card company, also wanted to erase the boundaries and distances between its offices in North America, South America, Europe, and Asia.

"Now we have people hitting the WebNative Venture database all the time from all over the world,"said Greg Pedersen of Topps, which employs more than 420 people worldwide.

"We have two main vendors outside, tons of different users coming in on our server using WebNative and sending files and doing work, not to mention globally we have Topps in England, Topps in Italy, Topps in South America, manufacturers in China, and design places everywhere. They all have WebNative accounts that access the images on our server. There are no FTP sites that they have to go on. We don't use FTP sites, just WebNative, and for them it's very easy. Within five minutes we can make them an account and they just log in through any browser and they are sending their files," Pedersen said.

\section{AN ORGANIZED DIGITAL SUPPLY CHAIN EQUALS SPEED}

Thanks to a history that dates to 1938 and because of today's modern digital cameras that shoot pictures at breathtaking speed, Topps has an enormous library of digital photographs.

"Our photo crew goes through thousands and thousands of images. For example, when we start baseball Spring Training, we've got photographers shooting away with their camera like a machine gun. With those fast cameras, they shoot so many digital pictures that the players look animated. The photo editors then weed out the shots that we're never going to use and with the WebNative Venture database, they put the rest of the images on the server," Pedersen said

Editors use custom fields in the Venture database to sort the images based on different poses that a sports editor looks for with each action shot, for example, with an arm extended out for a throw.

"That basic organization at the front end of the digital supply chain helps Topps keep track of its images from the start of production so products reach the shelves faster," Pedersen said.

In an industry as competitive as retail, every saved minute of production time means the department stores and retail and consumer giants are one minute closer to bringing in a customer and selling their goods.

"Obviously when you increase the speed of your production department, you increase the speed with which you get things to press, and you increase the speed with which you get ads to the newspapers," Schechter said.

"Retail is a fast-paced environment and we need to be able to get our ads and direct-mail pieces out on time. Everything is time-sensitive and time-crucial. If we can save an hour or two in the workflow, wherever it might be, to get a picture to an art director faster, or so a buyer can double-check an ad to make sure that it looks correct onscreen, if we can get it to press faster, we can get it to your door faster, and that means maybe you'll come in and get a good buy." 